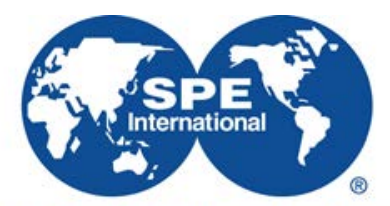

Society of Petroleum Engineers

\title{
SPE-197628-MS
}

\section{Improved Reservoir Characterization Through Rapid Visualization and Analysis of Multiscale Image Data Using A Digital Core Analysis Ecosystem}

\author{
Viswasanthi Chandra, King Abdullah University of Science and Technology; Gwenole Tallec, Thermo Fisher \\ Scientific; Volker Vahrenkamp, King Abdullah University of Science and Technology \\ Copyright 2019, Society of Petroleum Engineers \\ This paper was prepared for presentation at the Abu Dhabi International Petroleum Exhibition \& Conference held in Abu Dhabi, UAE, 11-14 November 2019. \\ This paper was selected for presentation by an SPE program committee following review of information contained in an abstract submitted by the author(s). Contents \\ of the paper have not been reviewed by the Society of Petroleum Engineers and are subject to correction by the author(s). The material does not necessarily reflect \\ any position of the Society of Petroleum Engineers, its officers, or members. Electronic reproduction, distribution, or storage of any part of this paper without the written \\ consent of the Society of Petroleum Engineers is prohibited. Permission to reproduce in print is restricted to an abstract of not more than 300 words; illustrations may \\ not be copied. The abstract must contain conspicuous acknowledgment of SPE copyright.
}

\section{Abstract}

Efficient integration of multiscale image and petrophysical data is becoming increasingly important to tackle emerging reservoir characterization challenges associated with complex carbonate and unconventional reservoirs. In this paper we illustrate an integrated digital rock physics and petrophysical data analysis methodology empowered by a digital core analysis ecosystem, for defining reservoir rock types and flow units in a micritic carbonate formation. We apply the methodology to 35 meters of cored well data acquired from the Late Jurassic Upper Jubayla Formation, equivalent to the lower Arab-D reservoir in Saudi Arabia. Pre-processing, segmentation and digital rock physics calculations are performed using whole core computed tomography (CT), plug micro-CT, thin-section micrographs and scanning electron microscopy data. Further whole core CT data analysis includes generation of mean intensity and heterogeneity logs. The digital rock ecosystem is applied to these multiscale image data and to spatially correlate with petrophysical well logs. The unique whole core CT processing step in the workflow allows the core barrels to be intelligently removed, and all the cores to be stitched together regardless of the total size of data. We thus access the full advantage of 3D whole core CT data that provides significantly high vertical resolution of rock properties in the well interval. Furthermore, the live ecosystem enables the continuous integration of image and petrophysical data as they become available over the duration of this study. Results from digital image analysis reveal the micro- and macro-pore types and their connectivity across multiple scales. Combined with plug and thin section data, log interpretation and digital image analysis, these pore types are upscaled into well log scale through texture-based rock-typing. The digital core analysis ecosystem we employ in this study has a unique capability of visualizing and analyzing large volumes of image and petrophysical data, allowing a novel method for rock-typing. The proposed methodology is scalable to data sets consisting of many wells, thus making it a valuable tool for accurate characterization of complex carbonate and shale reservoirs, which are becoming increasingly reliant on high resolution imaging techniques for pore space characterization. 


\section{Introduction}

The understanding of petrophysical and multiphase flow properties is essential for the assessment and exploitation of hydrocarbon reserves and these properties in turn are dependent on the 3D geometric and connectivity properties of the pore space. The application of multiscale image data for characterization of pore space in reservoir rocks has been gaining momentum over the past decade (Wellington and Vinegar 1987; Carlson 2006; Fitzsimons et al. 2016; Dernaika et al. 2017). Efficient utilization of multi-scale image and petrophysical data for characterizing complex rock formations requires a common platform that can handle large amounts of data to enable rapid visualization and analysis. In this paper we illustrate an integrated digital rock physics and petrophysical data analysis methodology empowered by a digital core analysis ecosystem, for defining reservoir rock types and flow units in a micritic carbonate formation.

\section{Data set}

In this study we used 35 meters of cored well data acquired from the Late Jurassic Upper Jubayla Formation, equivalent to the lower Arab-D reservoir in Saudi Arabia. Multi-scale image data acquired include whole core computed tomography (CT) scans for the entire well interval, micro-CT scans of selected core plugs, thin section micrographs and scanning electron microscopy (SEM) images of subsamples extracted from trim-ends of over 100 core plugs. Plug porosity and permeability measurements and x-ray diffraction (XRD) analysis was performed on all these core plugs. Depositional facies versus depth log was obtained from core description of slabbed cores.

The mineralogy in the upper sections of the core interval is predominantly calcite, whereas the lower sections have a variable distribution of dolomite and quartz rich facies (Figure 1A). The main depositional facies in the well, as observed from slabbed cores, are bioturbated mudstones, dolomitic mudstones, stromatoporoid wackstone-packstones, and grain dominated rudstones and floatstones (Chandra et al. 2019). Thin section petrography indicates strong diagenetic alteration of the rock by telogenic processes including intensive micrite recrystallization (Figure 1B) and dedolomitization (Figure 1C). The core plug porosity and permeability distributions are poorly correlated with depositional facies due to the ubiquitous overprint of post-uplift diagenetic processes on the rock fabric (Figure 2). 

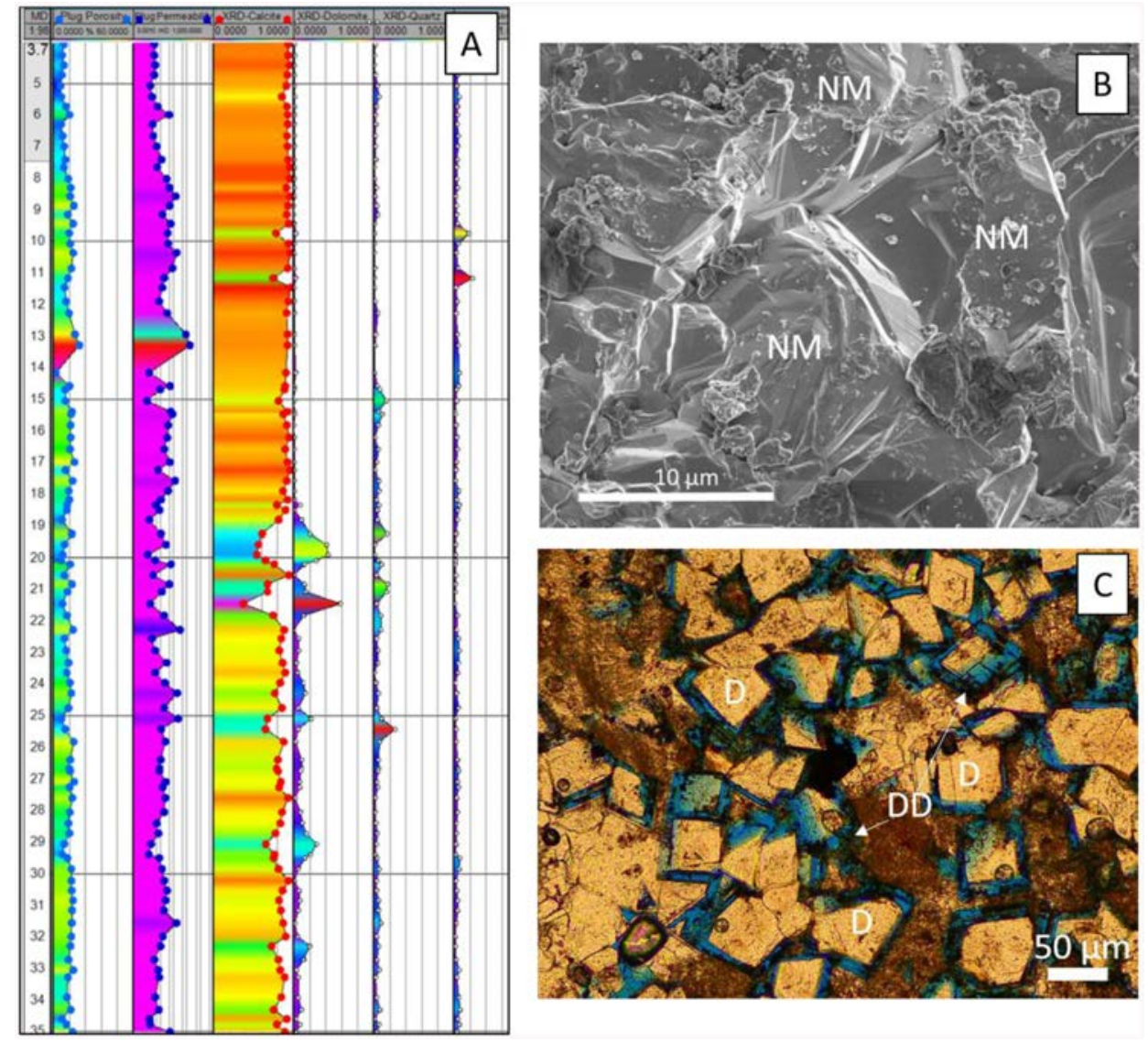

Figure 1-(A) Correlation panel of DQ well core plug data used in this study. From left to right: measured depth [m], plug porosity [p.u], plug permeability [mD], XRD profiles of calcite, dolomite, quartz and clay minerals. Note the abundance of calcite dom inated facies in the top sections of the well and presence of dolomite and quartz rich facies in the lower sections of the well. (B) SEM image showing neomorphic microsparite [NM], possibly a product of post uplift diagenetic processes. (C) Thin section micrograph showing the evidence for dedolomitization [DD], manifested by the leached rim around the dolomite crystals [D].

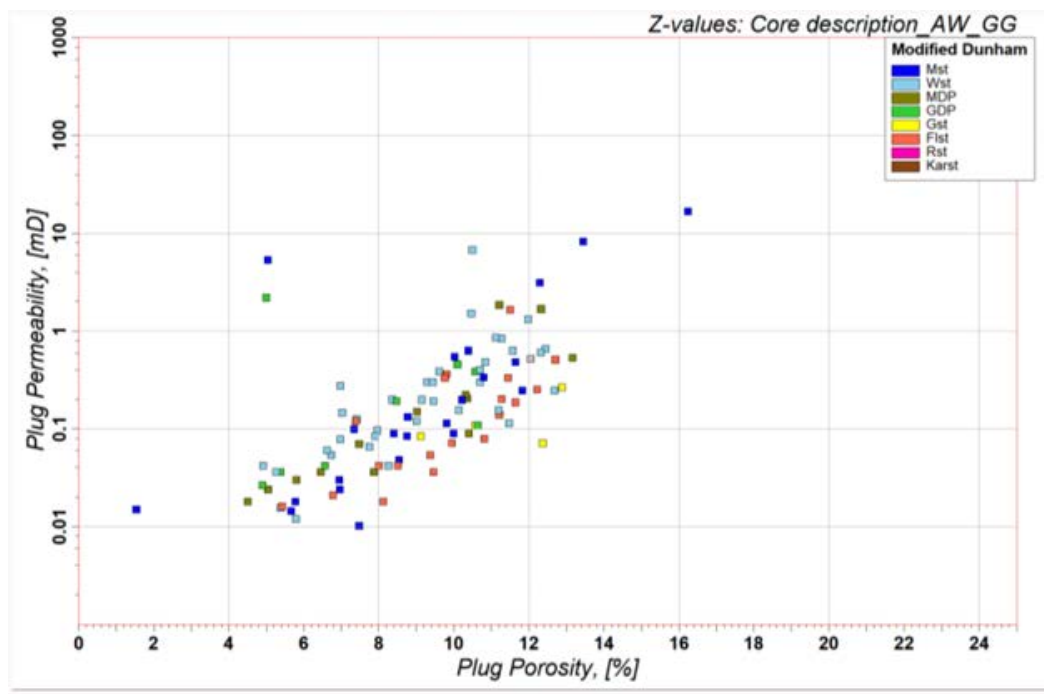

Figure 2-Cross plot of core plug porosity and permeability showing lack of trend with respect to depositional facies due to diagenetic overprint. 


\section{Whole core CT image analysis}

There has been an accelerated increase in the application of whole core $\mathrm{CT}$ data for reservoir characterization over the past years (Victor et al. 2017; Dernaika et al. 2017; Al-Owihan, et al. 2014). Hurst (1984) took a significant step forward to adapt medical CT scanner to oil and gas industry lab studies, followed by Shell scientists' (Vinegar and Wellington 1987) pioneering work, who modified medical CT scanner for core analysis. Current multi-slice CT systems are capable of continuous scanning, down to $0.5 \mathrm{~mm}$ resolution, of a three foot core in helical mode in a matter of minutes and are being rapidly applied to fluid transport studies. The main advantage of whole core CT scanning is that it provides a noninvasive method of obtaining 3D images that can provide continuous density and mineralogy estimations across the well intervals much higher vertical resolution compared to wireline data. When combined with other petrophysical and multiscale image data, as demonstrated in this paper, whole core CT data analysis can be a very efficient characterization tool to bridge the gap between core and reservoir grid block scales.

The whole core CT data used in this study was acquired using a medical CT scanner at voxel resolution of $0.625 \mathrm{~mm} \times 0.625 \mathrm{~mm} \times 0.625 \mathrm{~mm}$. The operating parameters used for scanning were $100 \mathrm{~mA}$ of current and $120 \mathrm{kV}$ voltage, in the helical scan mode. The radiographs were reconstructed and exported in DICOM format, which were used for visualization and further processing using the digital core analysis ecosystem.

\section{Preprocessing}

The first step of preprocessing included automated cropping and centering of the core CT images to remove the noise generated by the scanner and sample holder (Figure 3A-B). The next step was to apply beam hardening correction (Figure 3C-D), using a linearization procedure. Beam hardening is one of the most important artefact in CT images, caused by preferential attenuation of low-energy X-rays when a polychromatic X-ray beam passes through an object. As seen in Figure 3C-D, the contrast between the high and low density materials in the rock improved significantly after beam hardening correction. These preprocessing steps are essential to prepare the core CT data for further quantitative analysis and were performed on all the cores simultaneously using the digital core analysis ecosystem, which enabled the cores to be stitched together regardless of the total size of data.
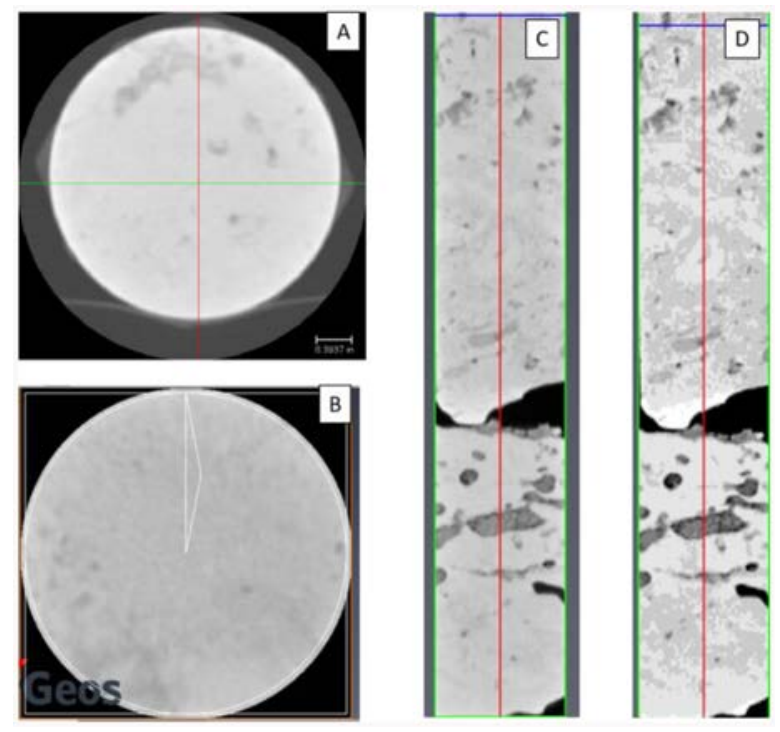

Figure 3-Whole core CT data before (A) and after (B) cropping the image data to remove noise, and before (C) and after (D) application of beam hardening correction. 


\section{Data analysis}

Following the preprocessing steps, the core CT image data was used for qualitative and quantitative analysis. Qualitative analysis entailed visual inspection of the core CT images to identify 'textures' (Figure 4A) based on variations in the gray scale, which are representative of geological-petrophysical heterogeneities potentially controlling the reservoir quality at the well scale. The CT textures can be correlated with rock properties such as porosity and permeability in the corresponding well sections, and can contribute to rocktyping.

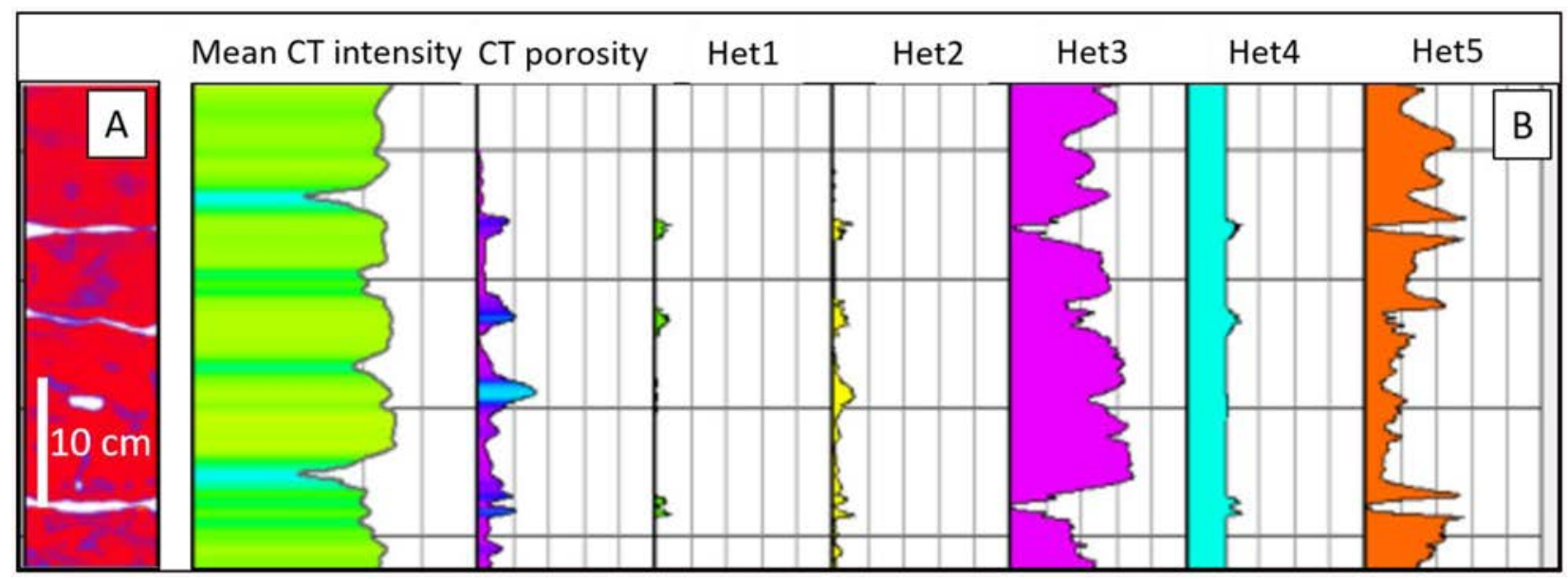

Figure 4-(A) Example of CT textures identified from whole core CT images and corresponding correlation panel in the digital ecosystem (B) showing the mean intensity, CT porosity and core heterogeneity logs (Het1-Het5) computed from whole core CT images.

Quantitative analysis included the computation of attributes using the grey scale distributions in each slice, generating a high resolution continuous logs along the entire well interval. The logs computed from the whole core CT images hence represent the entire core length and volume at the sub-millimeter resolution, and enable core to log depth matching. The CT attributes computed for this study are mean intensity, CT heterogeneity and CT porosity (Figure 4B). The mean intensity log was extracted using autothresholding in order to get rid of the empty spaces between the cores, and then computation of mean CT value for each slice. The CT porosity log was generated by an automated image processing protocol involving masking of the 35 meters of core with automated thresholding and binary morphology to get rid of the few remaining bordering pixels inducing beam hardening, and a micro-CT cross correlated segmentation routine. This step is discussed further in a later section in this paper.

\section{Heterogeneity logs}

The heterogeneity logs were computed from the greyscale histogram for every $x-y$ slice of the core within a fixed range. Histogram bins were obtained such that they were equally distributed across the grey scale range, and for each of these bins a log was generated. For a given slice, i.e. depth, the log value represents the number of pixels within that grey value histogram bin (Figure 5). So low number of bins indicate homogeneous rock, while numerous bins means the rock is very heterogeneous and possibly contains multimodal pore size distributions (Fitzsimons et al. 2016). The histogram logs hence show how the composition of rock varies for every slice of the core CT image. In addition, the trends identified using the heterogeneity logs can be correlated with sequence stratigraphy interpretations and can contribute to rocktyping. We demonstrate how the CT textures and heterogeneity log signatures are correlated with plug scale rock types in a later section in this paper. 


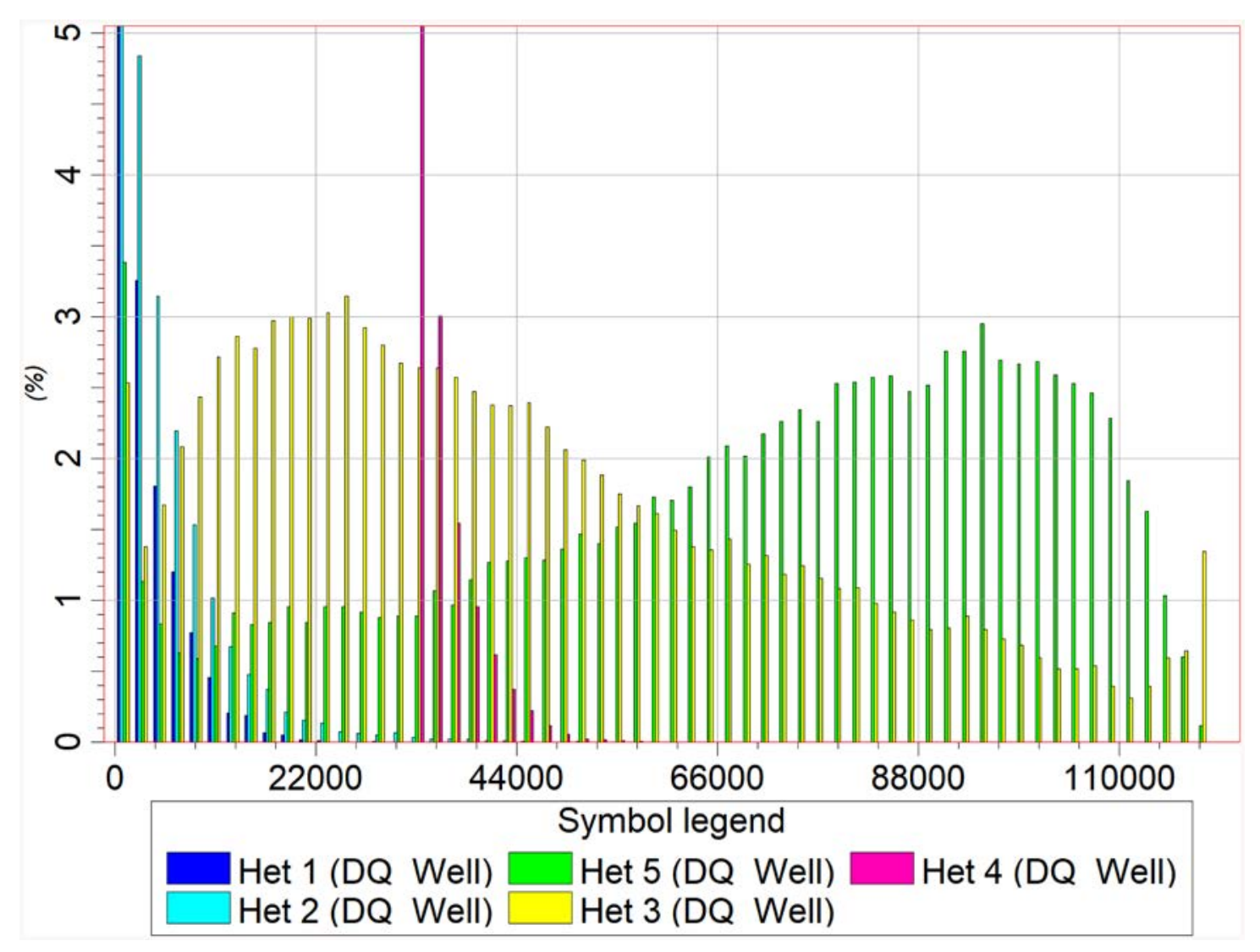

Figure 5-Histograms indicating the distribution of grey value representative of each heterogeneity log across the well interval.

\section{Core plug data analysis}

Over 100 standard core plugs were drilled from the whole cores at a regular spacing of 1 foot. The trim ends from the plugs were used for thin section, XRD and SEM analyses. Helium porosity and air permeability measurements were performed on the trimmed 1" diameter x 3 " length core plugs.

\section{Petrophysical analysis}

In order to characterize the core plugs based on similar flow properties, Flow Zone Indicator (FZI) (Amaefule et al. 1993) values were calculated from plug porosity and permeability using Equation 1 below.

$$
F Z I=\frac{0.0314 * \sqrt{ }\left(\frac{K}{\emptyset}\right)}{\frac{\emptyset}{(1-\emptyset)}}
$$

Equation 1. Calculation of $\mathrm{FZl}$, where $\mathrm{K}$ and $\Phi$ are plug permeability and porosity, respectively.

Three main petrophysical groups-RT1, RT2 and RT3- were classified based on FZI, porosity and permeability distributions as shown in Figure 6. Typically, the petrophysical rock types derived from FZI are used to identify the flow units at the well log scale, which are then directly distributed in the reservoir model. However, this approach often does not warrant adequate representation of multi-scale geologicalpetrophysical heterogeneities, especially in microporous carbonate reservoirs. It is hence important to commensurate these plug-scale petrophysical rock types with respect to pore- to core-scale heterogeneities that contribute to fluid flow at the grid-block scale. The multi-scale data analysis approach used in this study allowed this correlation to enhance the definition of reservoir rock types. 


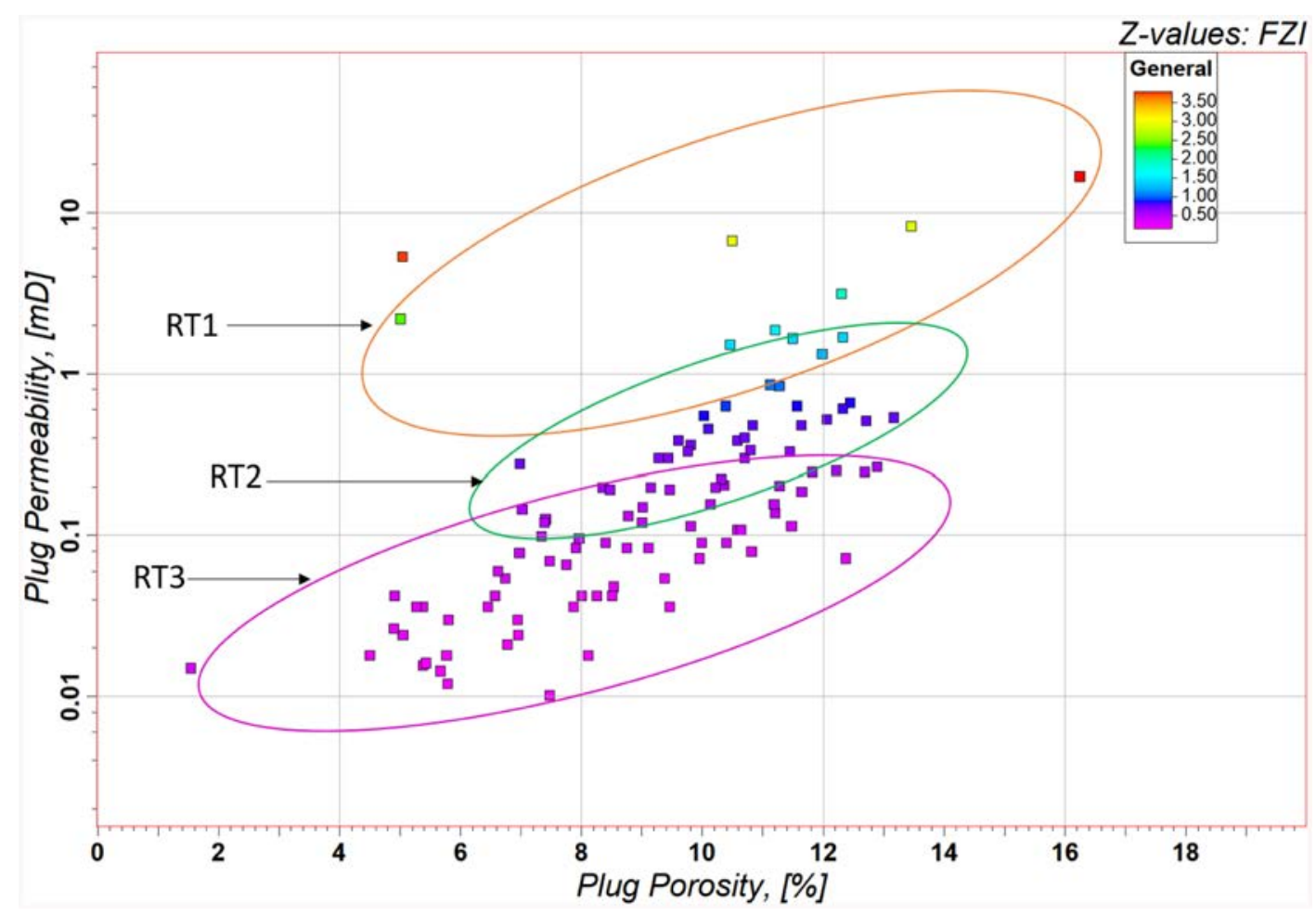

Figure 6-Core plug porosity-permeability cross-plot showing three main trends, RT1, RT2 and RT3, based on flow zone indicator (FZI) values.

\section{Pore-typing and microtexture analysis}

Thin section images enabled the visualization of sub-millimeter scale rock fabric and the distribution of micro- and macro-pores. Pore types were identified using (Lucia 1995)'s classification. The main pore types identified are intergranular, intragranular, separate vug, touching vug and intercrystalline porosity. SEM analysis of broken samples allowed the characterization of micrite microtextures at the micro-meter scale. Micrite is the product of micritization, which transforms carbonate sediment grains into fine-grained microcrystalline calcite, characterized by a crypto- to microcrystalline crystal texture (Flugel 2010). Several earlier studies (Hashim and Kaczmarek 2019; Kaczmarek, Fullmer, and Hasiuk 2015; Fullmer et al. 2014; Lambert et al. 2006; Moshier 1989; Budd 1989) discussed the important role micrite plays in controlling the reservoir quality. We used the SEM images to identify and classify the micrite types based on the approach by (Deville de Periere et al. 2011), to be correlated with the petrophysical rock types. The main types of micrite observed are rounded, subrounded, anhedral compact and fused. SEM imagery also indicated the presence of intracrystalline pores widespread in some of the dolomite rich samples

\section{Pore connectivity at plug scale}

Micro-CT images of three plugs, each representative of one of the three plug-scale rock types RT1, RT2 and RT3 were obtained at a voxel resolution of $20 \mu \mathrm{m}$ x $20 \mu \mathrm{m} \times 20 \mu \mathrm{m}$. Digital image analysis of plug micro-CT data was implemented, including noise reduction with a Non Local Means algorithm, and semiautomated segmentation of the pore space with a 3D marker based watershed obtained from thresholded markers, enriched with a black TopHat transform. Results from digital image analysis of micro-CT images when compared with thin section and SEM images revealed the micro- and macro-pore types and their connectivity across multiple scales for each of the plug-scale rock types. Figure 7 illustrates the results from micro-CT imaging of rock type RT1 before and after pore space segmentation, and how the macro-pore space is connected in $3 \mathrm{D}$. 

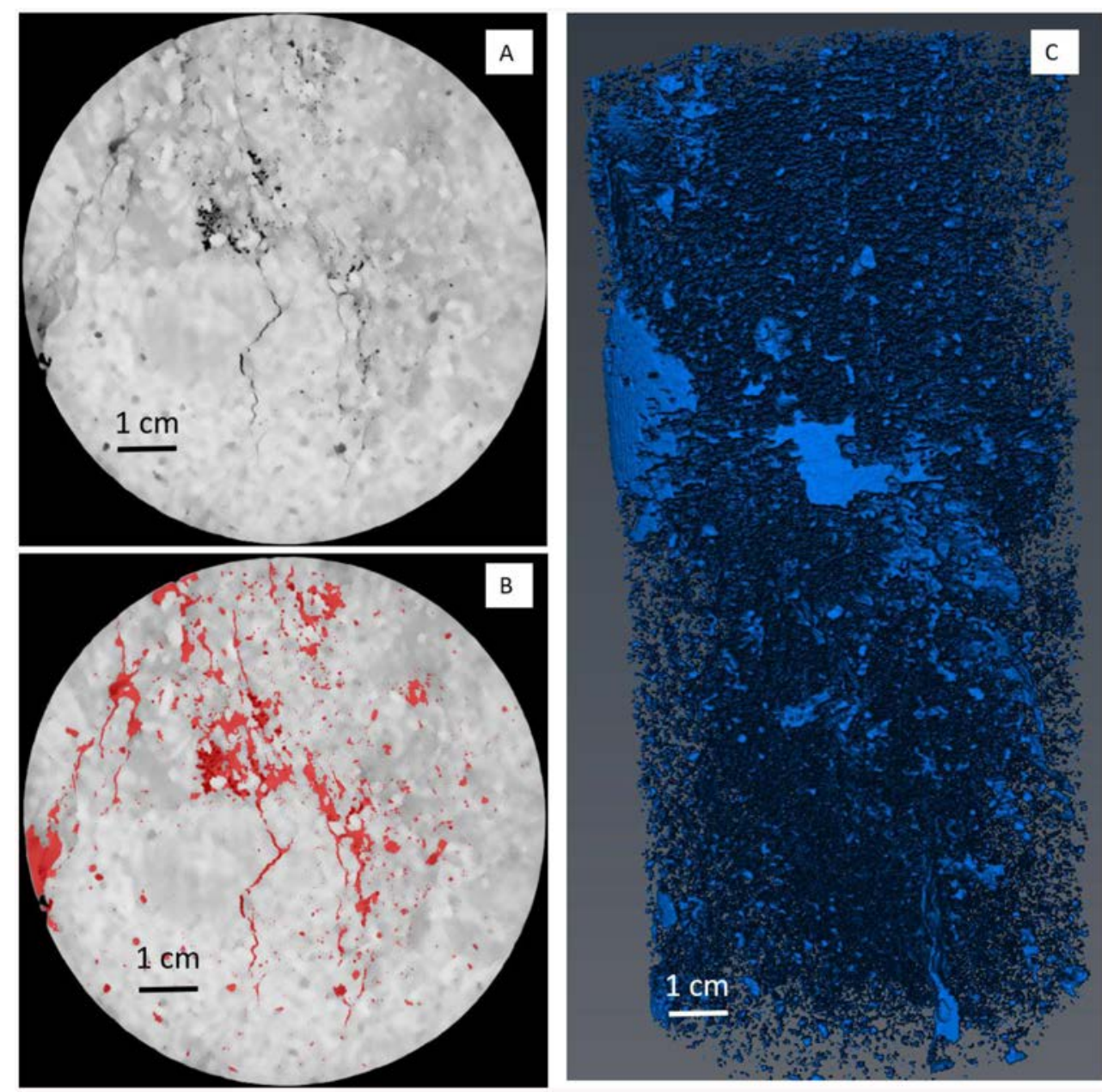

Figure 7-Micro-CT image of core plug representative of rock type RT1 showing x-y cross-section of the greyscale image before (A) and after (B) segmentation of macro-pore space. (C) Volume rendering of segmented macro-pore space in 3D showing good connectivity. Note that microporosity is not fully resolved at this scale.

\section{Multi-scale image and petrophysical data analysis}

The digital core analysis ecosystem used in this study enabled the visualization and analysis of the multi scale image data discussed in the above sections, including the whole core data for the entire well interval. We were thus able to take full advantage of 3D whole core CT data, which provided significantly high vertical resolution of rock properties in the well interval. Furthermore, the live ecosystem enabled the continuous integration of image and petrophysical data as they became available over the duration of this study. Figure 8 illustrates how the user interface enabled the analysis and spatial correlation of the full suite of image and petrophysical data used in this study. 


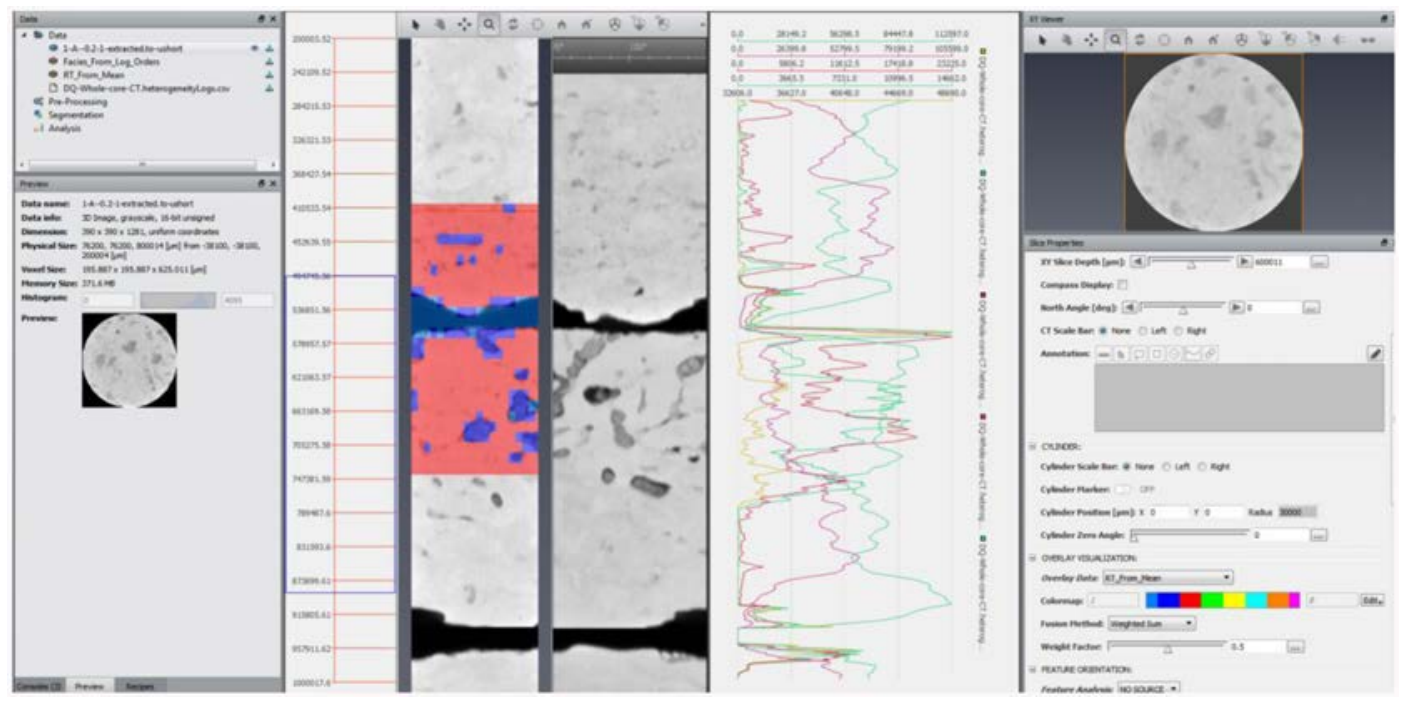

Figure 8-The digital rock ecosystem used to visualize to core CT image data and to spatially correlate with petrophysical well logs.

\section{Rock-typing using multi-scale data}

The distribution of the petrophysical rock types along the well interval and the typical microtextures and pore types observed from thin sections are illustrated in Figure 9. The main controls of rock quality at the micro- to plug-scale are pore type and mineralogy. The pore types are mainly influenced by the diagenetic products of micritization, micrite recrystallization and dedolomitization. Figure 11 illustrates the micrite microstructures typically observed in the SEM images for each rock type.

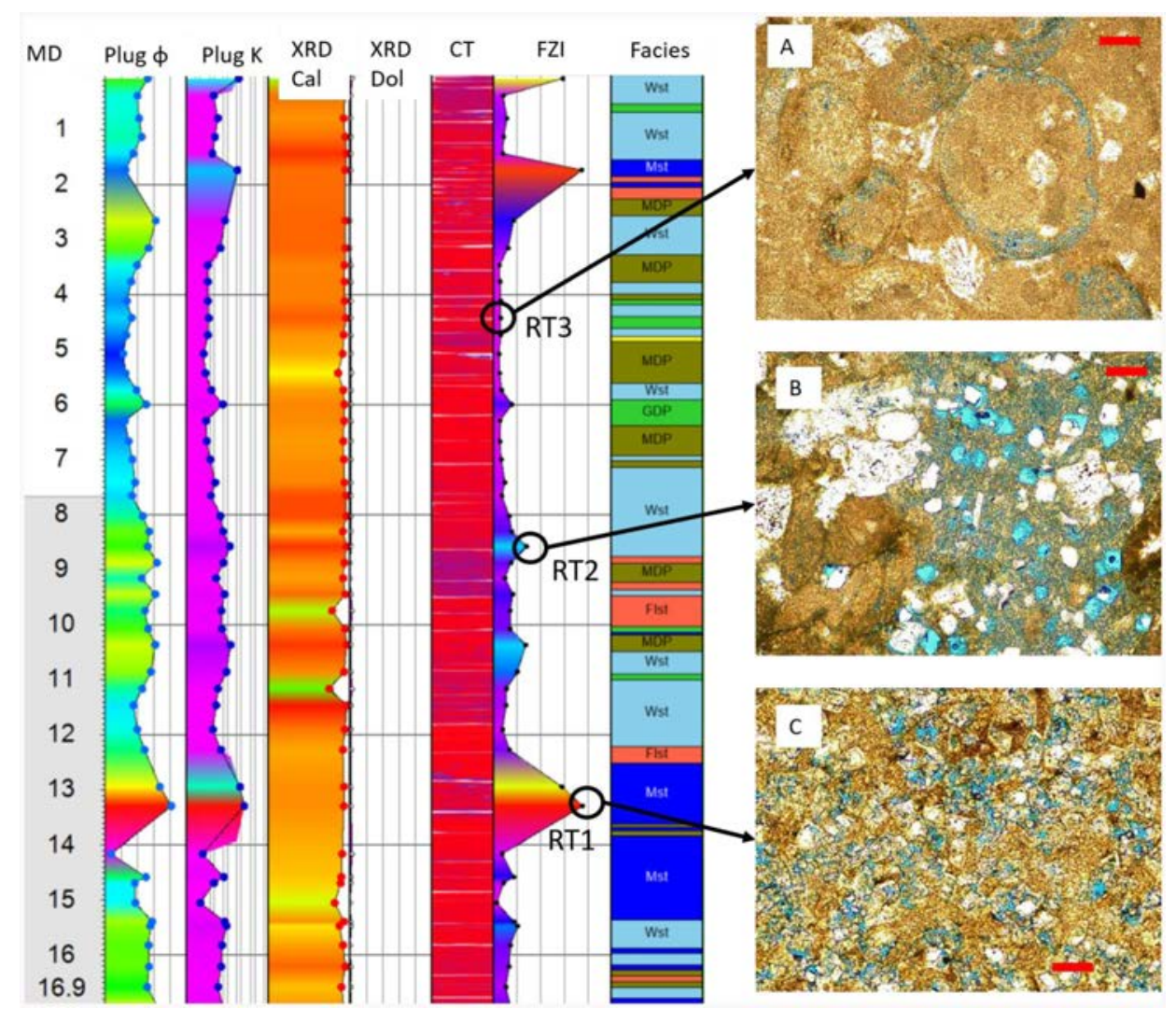

Figure 9-Distribution of flow zone indicator (FZI) log and the thin section micrographs representative of the rock types RT3 (A), RT 2 (B) and RT1 (C) from the corresponding depths. The scale bar on thin section micrographs is $50 \mu \mathrm{m}$. 


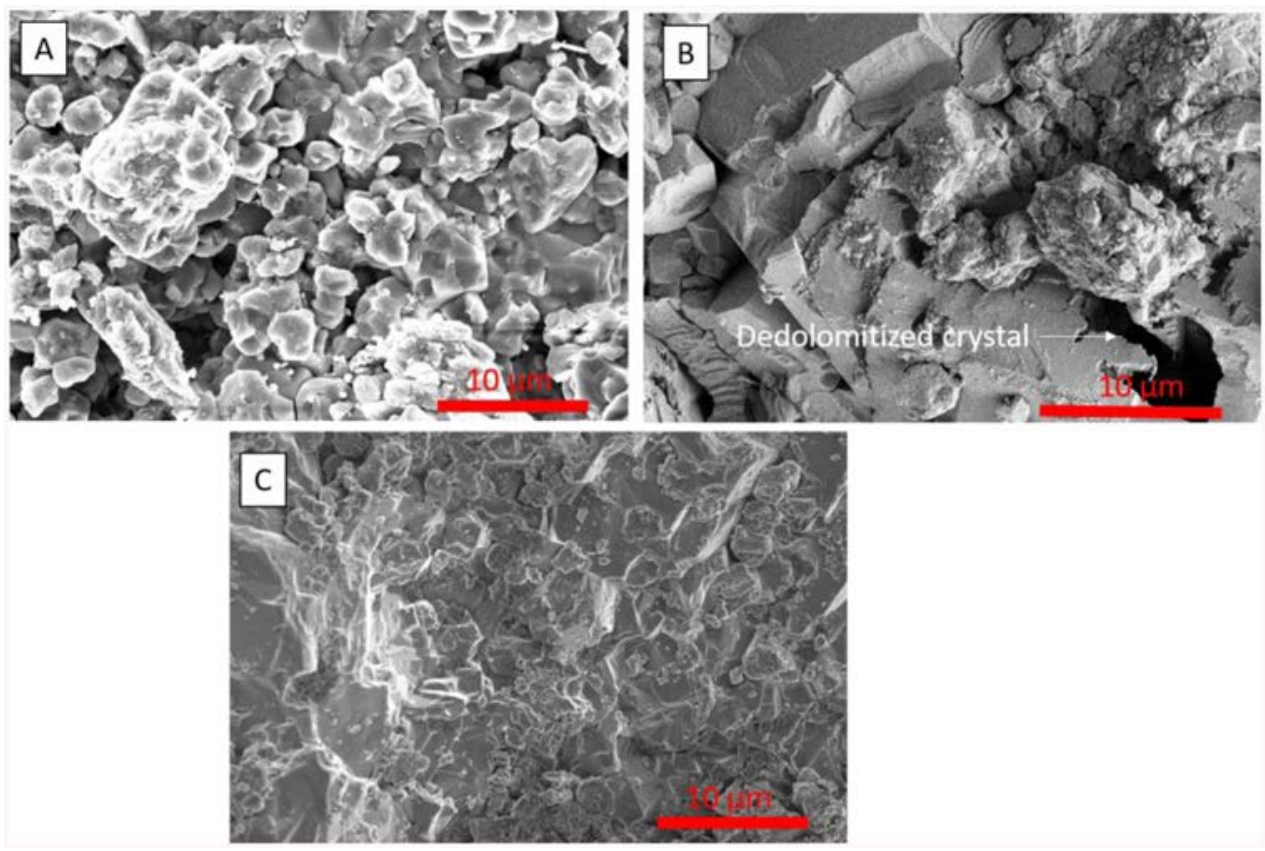

Figure 10-SEM images illustrating the typical micrite microtextures in the three rock types (A) RT1 is mainly composed of rounded to sub-rounded micrite, (B) RT2 has a combination of anhedral and subrounded micrite surrounded by dedolomitized crystals and (C) RT3 has mainly anhedral compact and fused micrite.

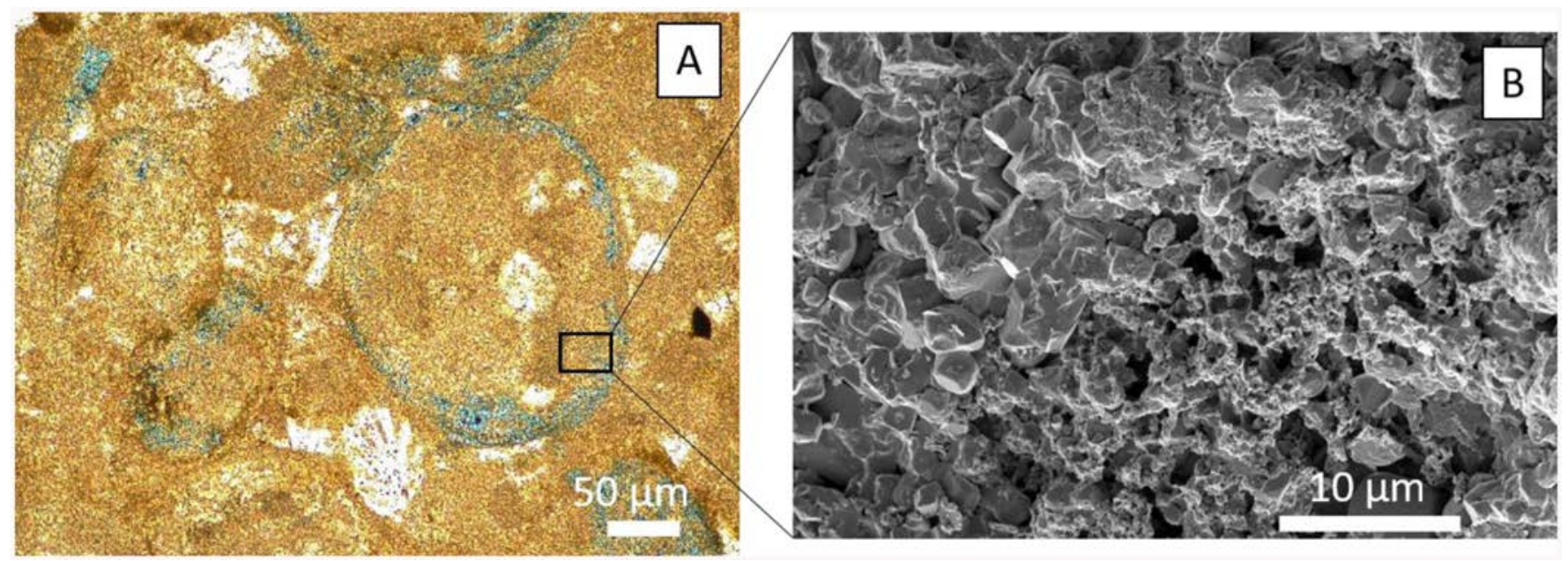

Figure 11-Comparison of SEM and thin-section images from rock type RT3 to characterize the pore scale heterogeneity. It is evident from thin section micrograph $(A)$ that the overall micro- and macropore connectivity is poor although the SEM image (B) indicates well connected microporosity.

The rock type RT1 represents the best quality core plugs in the well interval, with permeability ranging from 1 to $10 \mathrm{mD}$. The pore types in RT1 observed from thin section are mainly intergranular, separate and touching vug porosity types. The mineralogy is predominantly calcite, with some dolomite. SEM images showed that micrite microtexture is mainly composed of rounded to subrounded micrite, with wellconnected micro- and macro-pores.

RT2 type plugs contained higher amounts of dolomite and quartz than RT1, with permeability values ranging from 0.1 to $1 \mathrm{mD}$. The main pore types observed in RT2 are intergranular, separate vug, inter- and intracrystalline porosity. SEM image analysis confirmed the presence of intracrystalline porosity associated with dolomite (Figure 11B) and showed a combination of rounded and anhedral compact type micrite in the intercrystalline space hosted by dolomite. 
RT3 type plugs were composed of calcite and variable amounts of dolomite, with permeability values ranging from 0.01 to $0.2 \mathrm{mD}$. Thin section observations showed the presence of intragranular pore type, and very little connected macro-pore space. SEM images indicated high levels of anhedral compact and fused nonporous micrite. Thin section and SEM images also indicated the abundant presence of microsparite resulting from micrite recrystallization. Although the RT2 samples in the lower sections of the well showed similar mineralogy as RT2 owing to the presence of dolomite, the pore connectivity and permeability was poor compared to RT2 samples in the dolomite rich samples due to lack of dedolomitization (Figure 11).

\section{Connecting the plug and whole core scales}

The whole core scale typically dominates the flow properties and suitable for comparison with well log resolution and volume of investigation. Establishing a scalable link between plug scale rock types and core scale features improves the definition of reservoir rock types. The well intervals hosting the three plug scale rock types RT1, RT2 and RT3 were compared to the whole core CT textures and heterogeneity logs. Figure 12 presents the CT textures corresponding to each rock type, illustrating the coherence between the rock petrophysical properties and distribution of grey values in the whole core CT images. These CT textures are associated with typical CT heterogeneity log signatures corresponding to each rock type (Figure 13). We were thus able to correlate CT textures and heterogeneity log signatures with each of the rock types reflecting the respective FZI, pore type and micrite distributions. In doing so, we were able to mitigate any possible under-representation by the core plugs of the high permeability features well connected at the core scale. In addition, the heterogeneity logs can be used as input for machine learning algorithms for prediction of rock types in uncored wells. Figure 14 presents the summary of the multi-scale image data and rock attributes used to define the rock types in this study.
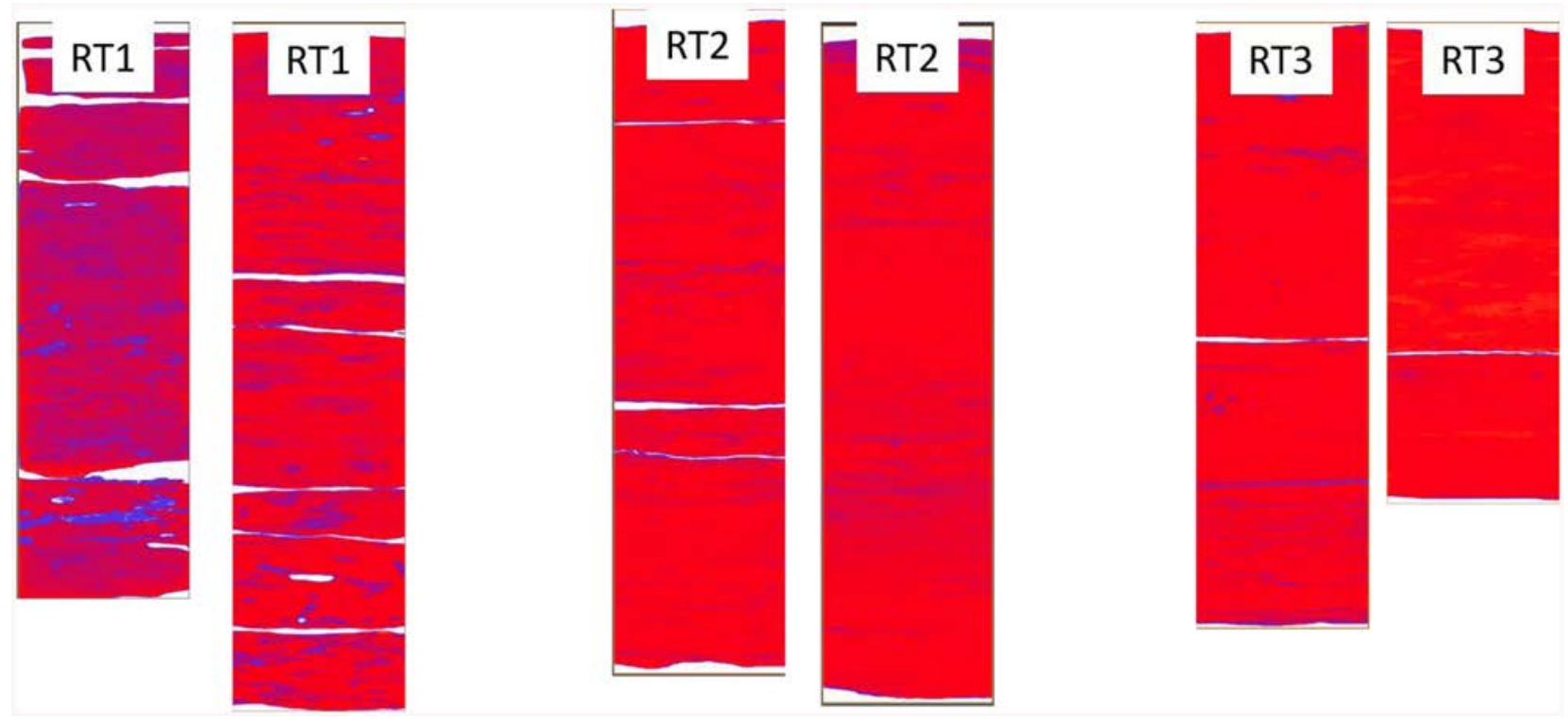

Figure 12-CT textures corresponding to each rock type, illustrating the coherence between the rock petrophysical properties and distribution of grey values in the whole core CT images 

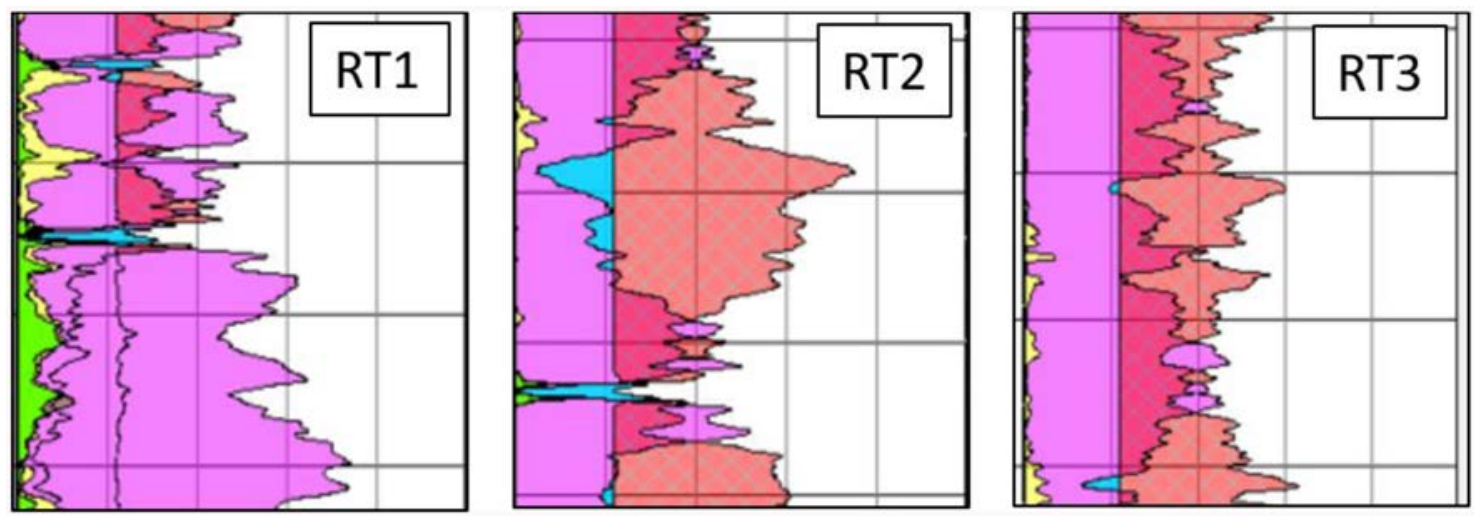

Figure 13-CT heterogeneity log signatures corresponding to each reservoir rock type.

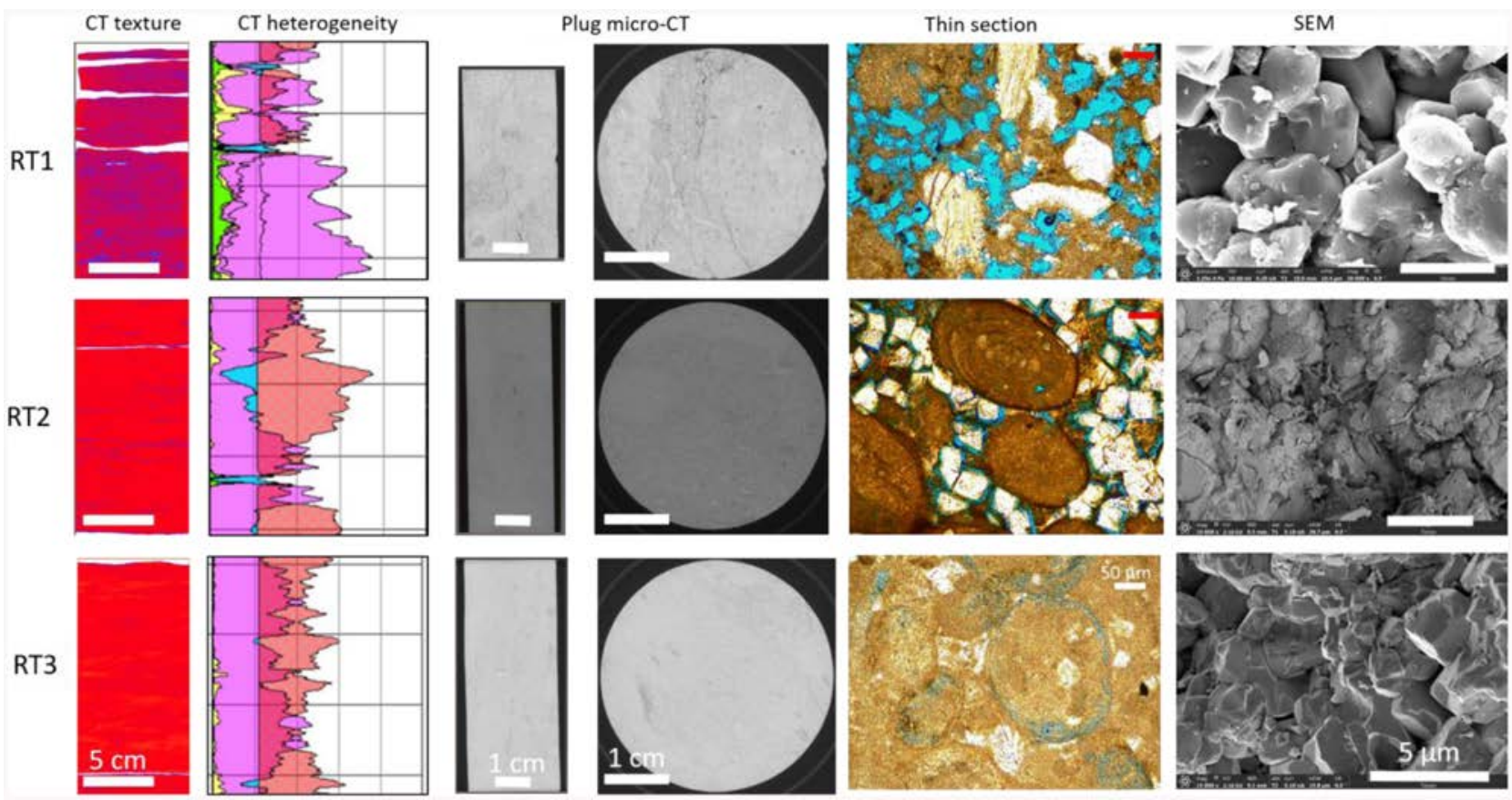

Figure 14-Summary of the multi-scale image data used for rock-typing at the well log scale, demonstrating the rock heterogeneity from pore to core plug to well log scale.

Furthermore, plug and core scale CT data was integrated to improve the accuracy of core CT derived porosity log. As discussed earlier, the pore space at the whole core CT scale was extracted with a combination of a 3D marker based watershed segmentation with markers set by absolute thresholding, enhanced with a black TopHat transform. However, microporosity and a significant portion of macro-pores were unresolved at the CT scale. To address the unresolved porosity, selected core plugs were scanned with a micro-CT at the resolution of $20 \mu \mathrm{m}$. The plug micro-CT images were then 3D registered with the whole core, in order to calibrate the pore space segmentation parameters of the whole core, so that matching 3D volumes at different resolutions reflect the same porosity. The porosity log derived from whole core CT data in this way is of much higher vertical resolution compared to core plug or wireline porosity. A continuous permeability log estimated from this, using the appropriate porosity-permeability transform, is therefore more reliable for further upscaling and reservoir property modelling. Permeability transforms for each rock type can be extended to multiple wells using this methodology and can be applied for permeability modelling at the reservoir scale. Figure 15 shows an example of how whole core permeability can be obtained from CT data. 

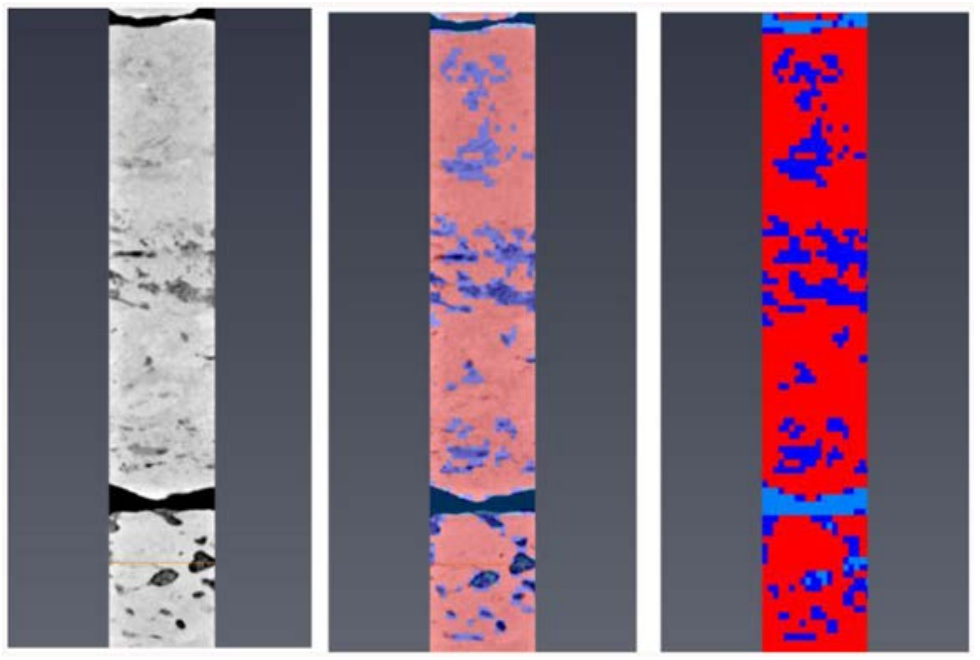

Figure 15-Obtaining permeability at the core scale; (A) 3D distribution of grey scale from whole core CT (B) pore space segmentation guided by multi-scale data analysis and (C) scan volume discretized into high resolution grid with porosity distribution to be used for flow based computation of permeability.

\section{Conclusions}

The digital core analysis ecosystem we employed in this study enabled visualization and analysis of large volumes of image and petrophysical data, allowing an efficient method for rock-typing. Analysis of thin section and SEM images revealed the presence and connectivity micro- and macro-pore types, which were coherent with plug-scale petrophysical rock types based on FZI. The textures in the whole core CT data and the CT derived heterogeneity logs were correlated with plug-scale rock types. Combined with plug and thin section data, log interpretation and digital image analysis, core plug scale rock types were upscaled into well log scale through texture-based rock-typing. These rock types can be used to generate upscaled porositypermeability transform that can be extended to multiple wells and enable better inter-well log correlation. The proposed methodology is scalable to data sets consisting of many wells, thus making it a valuable tool for accurate characterization of complex carbonate reservoirs.

\section{Acknowledgments}

The research presented in this paper is funded by King Abdullah University of Science and Technology (KAUST) through the Ali I. Al-Naimi Petroleum Engineering and Research Center (ANPERC). The authors thank Thermofisher Scientific and Schlumberger for providing access to the software PerGeos and Petrel, respectively. Special thanks to Elhadj Diallo (ANPERC lab team) and Marijn Boone (XRE) for their timely support in micro-CT scanning. Akbar Wicaksono and Gaurav Gairola (ANPERC) are thanked for their contributions to thin section petrography. We thank Ahmad Ramdani (ANPERC) for the core petrophysical measurements.

\section{References}

Al-Owihan, H., Al-Wadi, M., Thakur, S., Behbehani, S., Al-Jabari, N., Dernaika, M. and Koronfol, S. 2014. "IPTC 17625 Advanced Rock Characterization by Dual-Energy CT Imaging : A Novel Method for Complex Reservoir Evaluation." International Petroleum Technology Conference. https://doi.org/10.2523/IPTC-17625-MS.

Amaefule, Jude O, Mehmet Altunbay, Djebbar Tiab, David G Kersey, and Dare K Keelan. 1993. "Enhanced Reservoir Description: Using Core and Log Data to Identify Hydraulic (Flow) Units and Predict Permeability in Uncored Intervals/Wells." SPE Annual Technical Conference and Exhibition, no. c. https://doi.org/http:// dx.doi.org/10.2118/26436-MS.

Budd, David A. 1989. "Micro-Rhombic Calcite and Microporosity in Limestones: A Geochemical Study of the Lower Cretaceous Thamama Group, U.A.E." Sedimentary Geology 63 (3-4): 293-311. https:// doi.org/10.1016/0037-0738(89)90137-1. 
Carlson, William D. 2006. "Three-Dimensional Imaging of Earth and Planetary Materials." Earth and Planetary Science Letters 249 (3-4): 133-47. https://doi.org/10.1016/j.epsl.2006.06.020.

Chandra, V, A I Ramdani, T Finkbeiner, B Yalcin, P Khanna, and A Petrovic. 2019. "Comprehensive Characterization of Arab-D Reservoir Equivalent Outcrop Well Cores from Upper Jubaila Formation, Saudi Arabia." In 81st EAGE Conference and Exhibition, London. https://doi.org/10.3997/2214-4609.201901464.

Dernaika, Moustafa R., Bashar Mansour, David Gonzalez, Safouh Koronfol, Faris Mahgoub, Osama Al Jallad, and Mauricio Contreras. 2017. "Upscaled Permeability and Rock Types in a Heterogeneous Carbonate Core from the Middle East." In SPE Reservoir Characterisation and Simulation Conference and Exhibition . https:// doi.org/10.2118/185991-ms.

Deville de Periere, Matthieu, Christophe Durlet, Emmanuelle Vennin, Laurent Lambert, Raphael Bourillot, Bruno Caline, and Emmanuelle Poli. 2011. "Morphometry of Micrite Particles in Cretaceous Microporous Limestones of the Middle East: Influence on Reservoir Properties." Marine and Petroleum Geology 28 (9): 1727-50. https://doi.org/10.1016/ j.marpetgeo.2011.05.002.

Fitzsimons, Daniel, Gunnar Oeltzschner, Christopher Ovens, Dirk Radies, Wintershall Middle, and East Gmbh. 2016. "SPE-183145-MS Integration and Data Analysis of Conventional Core Data with NMR and CT Data to Characterize An Evaporitic Carbonate Reservoir."

Flugel, Erick. 2010. 5 Microfacies Data: Fabrics. Microfacies of Carbonate Rocks. Vol. 1. https://doi.org/10.1017/ CBO9781107415324.004.

Fullmer, Shawn M, Sean A Guidry, Jonas Gournay, Emily Bowlin, Gary Ottinger, Abdulla Al Neyadi, Bo Gao, and Ewart Edwards. 2014. "Microporosity : Characterization, Distribution, and Influence on Oil Recovery." Iptc.

Hashim, Mohammed S., and Stephen E. Kaczmarek. 2019. "A Review of the Nature and Origin of Limestone Microporosity." Marine and Petroleum Geology, April. https://doi.org/10.1016/J.MARPETGEO.2019.03.037.

Kaczmarek, S E, S M Fullmer, and F J Hasiuk. 2015. "A Universal Classification Scheme for the Microcrystals That Host Limestone Microporosity." Journal of Sedimentary Research 85 (10): 1197-1212. https://doi.org/10.2110/jsr.2015.79.

Lambert, Laurent, Christophe Durlet, Jean Paul Loreau, and Gérard Marnier. 2006. "Burial Dissolution of Micrite in Middle East Carbonate Reservoirs (Jurassic-Cretaceous): Keys for Recognition and Timing." Marine and Petroleum Geology 23 (1): 79-92. https://doi.org/10.1016/j.marpetgeo.2005.04.003.

Lucia, F Jerry. 1995. "Rock-Fabric / Petrophysical Classification of Carbonate Pore Space for Reservoir Characterization 1" 9 (9): 1275-1300. https://doi.org/10.1306/7834D4A4-1721-11D7-8645000102C1865D.

Moshier, Stephen O. 1989. "Development of Microporosity in a Micritic Limestone Reservoir, Lower Cretaceous, Middle East." Sedimentary Geology 63 (3-4): 217-40. https://doi.org/10.1016/0037-0738(89)90133-4.

Victor, Rodolfo A., Maša Prodanović, and Carlos Torres-Verdín. 2017. "Monte Carlo Approach for Estimating Density and Atomic Number From Dual-Energy Computed Tomography Images of Carbonate Rocks." Journal of Geophysical Research: Solid Earth 122 (12): 9804-24. https://doi.org/10.1002/2017JB014408.

Vinegar, Harold J., and Scott L. Wellington. 1987. "Tomographic Imaging of Three-Phase Flow Experiments." Review of Scientific Instruments 58 (1): 96-107. https://doi.org/10.1063/1.1139522.

Wellington, E. M, and H. J Vinegar. 1987. "X-Ray Computerized Tomography." JPT, no. August. 